\title{
Predictors of Undetectable Plasma Viral Load in HIV-Positive Adults Receiving Antiretroviral Therapy in Southern Brazil
}

\author{
Marysabel Pinto Telis Silveira, Maria de Lourdes Draschler, \\ José Carlos de Carvalho Leite, Cezar Arthur Tavares Pinheiro \\ and Vera Lúcia da Silveira
}

\author{
Catholic University of Pelotas, University of \\ Caxias do Sul, Faculty of Medicine of the \\ Federal University of Pelotas, RS, Brazil
}

\begin{abstract}
Factors associated with undetectable viral load $(<80$ copies $/ \mathbf{m l})$ were investigated among nonpregnant adults in antiretroviral treatment in a specialized service for HIV/AIDS in Southern Brazil. Use of antiretrovirals was investigated in two interviews (one month interval). Clinical data were collected from the clinical records; viral load previous to adherence measurement was defined the viral load previous to the first interview; the final viral load, the viral load subsequent to the second interview (interval between measures approximately 6 months). Undetectable final viral load occurred in $48 \%$ of the patients and was positively associated with levels of treatment adherence $(p<0.001)$, being $19 \%$ for less than $60 \%$ of adherence and about $60 \%$ for adherence greater than $80 \%$. In the multivariate model, the odds of undetectable final viral load was four times greater for $\mathbf{8 0 - 9 4 \%}$ and $\geq 95 \%$ of adherence (CI 95\% 1,80-13,28; CI 95\% 1,73-9,53), compared with less than $60 \%$ adherence; it was greater for less than 6 months in treatment (OR = 3.37; CI 95\% 1.09-10.46); and smaller for viral load previous to adherence measurement $\geq 5.2$ $\log 10(\mathrm{OR}=0.19 ; \mathrm{CI95 \%} 0.06-0.58)$, adjusted for these variables and sex, age, clinical status, current immune status, group of drugs and interval between the two measurements of viral load. The crude odds were lower for age 16-24 years and use of Nucleoside Analog Reverse Transcriptase Inhibitors only, but these effects were not significant in the multivariate model. There was no evidence of effect of sex, clinical status, current immune status, and changes in treatment regimen. Treatment adherence gave the largest effect. Motivational interventions directed at adherence may improve treatment effectiveness.
\end{abstract}

Key Words: HIV, antiretroviral therapy, adherence, viral load, predictors, risk factors.
Antiretroviral therapy improves the survival and life quality of patients with HIV/AIDS [1-4] because it reduces viral load (concentration of RNA-HIV1) [5] and therefore causes a decrease in the destruction of $\mathrm{CD}_{4}$ lymphocytes, which improves the immune system

Received on 4 April 2002; revised 31 July 2002.

Address for correspondence: Dr. Marysabel Pinto Telis Silveira Rua Dom Pedrito 842, Laranjal - Pelotas - RS - Brazil, Zip code: 96090-230. E-mail: marysabel.s@uol.com.br-Telephone numbers: +55 (53) 226-1927; +55 (053) 9981-4029.

Sources of Financing: Catholic University of Pelotas and Research Support Foundation of the State of Rio Grande do Sul, Brazil.

The Brazilian Journal of Infectious Diseases 2002;6(4):164-171 (C) 2002 by The Brazilian Journal of Infectious Diseases and Contexto Publishing. All rights reserved. $1413-8670$ of the patient [6]. The quantification of the viral load in the plasma is a predictor of the progression of the disease [6-8] and, along with $\mathrm{CD}_{4}$ lymphocyte counts, has been used to monitor therapeutic responses $[7,9,10]$

Studies about determinants of undetectable viral load in patients in antiretroviral treatment are important but are still relatively scarce. Such studies show that the duration of treatment is one of the determining factors of viral load. The first 4 to 6 weeks of treatment are marked by a trend of reduction in viremia of at least $1.0 \log _{10}$, which represents $90 \%$ of the initial viremia and, in the next 12 to 24 weeks the viremia is expected to be undetectable or $99 \%$ lower than its initial level or from 5,000-10,000 copies/ml [6]. A cohort study indicates that the prevalence of undetectable viral load increases between 3 and 6 months of treatment, and 
that there is no evidence of changes in this prevalence after that period [11]; another study suggests that the reduction in viral load is greater during the first year of treatment [12].

The level of adherence to antiretrovirals has been considered the most important predictor of viral load in patients receiving treatment. Studies suggest that the viral load decreases $[13,14]$ and the prevalence of undetectable viral load increases [5,15-17] as adherence increases and high adherence rates are usually necessary for attaining therapeutic effectiveness. For example, another study showed a prevalence of undetectable viral load in $78 \%$ of the patients whose adherence rates were $95 \%$ or greater; this prevalence decreased to $39 \%$ in patients with adherence rates between $80 \%$ and $94 \%$ and to $20 \%$ in those whose adherence rate was less than $80 \%$ [5]. Another study found a strong linear association between undetectable viral load and adherence; in patients with adherence higher than $97 \%$ the prevalence of undetectable viral load was approximately $60 \%$ [15].

Other factors have also been investigated in terms of their effects on viremia. Higher prevalence of undetectable viral load and lower levels of viral load have been associated with age above 45 [18-19], female sex [18], stable immune status (evidenced by CD4 counts higher than 200 cells $/ \mathrm{mm}^{3}$ ) [18-20], and lower levels of viral load at the beginning of treatment [5,18,20-21]. On the other hand, prevalence of undetectable viral load tends to be lower for treatment regimens including only Nucleoside Analogue Reverse Transcriptase Inhibitor (NRTI) [22,23], or history of previous treatment comprised solely of NRTI [20]. There is no evidence of association between clinical stage and viral load $[19,20]$.

The studies about determinants of viral load in patients receiving antiretroviral treatment are still relatively scarce and further studies are needed in this area.

We investigated factors associated with undetectable viral load among non-pregnant adults who were receiving antiretroviral treatment in a public service specialized in HIV/AIDS located in southern Brazil.

\section{Materials and Methods}

All the patients chosen for this study were registered at the Service of Specialized Assistance for HIV/AIDS in the city of Pelotas, Brazil, and were receiving multiple antiretroviral therapy according to the 2000 Brazilian Consensus [24], regardless of duration of treatment and kind of antiretroviral regimen used. All patients were 13 years of age or older and none were pregnant. The trial was approved by the staff of the service and by the Scientific Commission of the Catholic University of Pelotas. All patients were interviewed on two different occasions (interval of one month between them) after a written informed consent was given to a trained interviewer who did not know the antiretroviral regimen prescribed. Most of the interviews were performed at the medical service; those patients who did not attend the service on a regular basis were called on at their homes. The period of interviews lasted from May, 2000, until July, 2001. All data were recorded twice.

The following variables were created based on information obtained from the interviews.

Socio-economic conditions: age, sex, schooling (in number of years completed) and household income (in units of the minimum wage) were asked about in the first interview.

Mean adherence to antiretrovirals: the use of antiretrovirals in the last 48 hours was investigated by self-report during the first and the second interview (interval of approximately one month between them). A time sheet was used to help the patient to remind about his/her routine activities (e.g., breakfast, lunch) and to report the medications in use, doses and schedule of administration. Mean adherence (first + second interview) was estimated as follows: initially, the percentage of adherence to each drug of the regimen was calculated by dividing the number of tablets taken in four days (first + second interview) by the number of tablets that had been prescribed. After that, the mean adherence to the regimen was estimated by the arithmetic mean of adherence to the drugs. 
Information copied from the clinical records was used to create the following variables:

Viral load previous to adherence measurement: last plasma viral load (quantification of HIV-RNA) previous to the first interview intended to measure adherence rate was obtained from the clinical records.

Final viral load: plasma viral load obtained subsequent to the adherence measurement (viral load and $\mathrm{CD}_{4}$ counts are routinely collected every four months for patients in antiretroviral therapy).

The measurements of viral load were performed by the NASBA method (Nucleic Acid Sequence Based Amplification) during periods of clinical stability, at least four weeks after immunizations, or during recovery from intercurrent infections, and always at the same laboratory accredited by the Ministry of Health in Brazil. The limit of detection with this method is 80 copies/ml.

Duration of antiretroviral treatment: Number of months between the beginning of the antiretroviral therapy and the date of the final viral load count, both extracted from the patients' clinical records.

Group of medicines in the antiretroviral regimen currently prescribed: the drugs were grouped according to their mechanism of action as: (a) Nucleoside Analogue Reverse Transcriptase Inhibitors (NRTI), (b) Non Nucleoside Reverse Transcriptase Inhibitors (NNRTI), (c) Protease Inhibitors (PI);

Number of drugs: drugs were grouped in double, triple or quadruple regimens;

Changes of regimens: there was an investigation about whether another antiretroviral regimen had previously been prescribed;

Current immune status: determined by $\mathrm{CD}_{4}$ lymphocyte counts closest to the adherence measurement; this was measured using flow cytometry.
Counts of 200 cells $/ \mathrm{mm}^{3}$ or higher indicate a stable immune status [10.24];

Clinical stage of disease caused by HIV: classified according to the recommendations of the Center for Prevention and Disease Control of the United States [2] and modified according to the criterion adopted in Rio de Janeiro/Caracas. Patients were classified in stage A (asymptomatic), stage B (with symptoms related to HIV) and stage $\mathrm{C}$ (with diseases that define AIDS or with 10 or more points according to criteria adopted by the Rio de Janeiro/Caracas consensus) [2,25].

The percentages of patients with undetectable final viral load and the odds ratio for undetectable final viral load, both crude and adjusted, were estimated for each exposure variable. It was established that the exposure variables that showed any effect upon undetectable final viral load in the crude model $(p<0.300)$ would be included in the final model as potential confounders of other exposure variables.

\section{Results}

Among the 322 patients registered who met the criteria for inclusion, 10 were already dead before the first interview and the remaining 312 patients were selected for the study. A total of $78 \%$ of the patients participated $(n=244), 2$ refused to participate, 35 were not found for the first interview, 4 for the second, 2 patients passed away before the second interview and 25 patients did not have the measurements of viral load. The ages of the patients ranged from 16 to 68 years, mean of 35 years, and the majority were men $(65 \%)$. Schooling ranged from zero to 16 years (mean of 6 years), and 38\% had less than five years of schooling. Household income ranged from zero to 46 minimum wages (mean of 2.5 minimum wages) and $16 \%$ had income below the minimum wage. Undetectable viral loads prior to adherence measurement was found in $12 \%$ of the patients, while this percentage was $48.4 \%$ for the final viral load. The majority of patients were classified as clinical stage $\mathrm{C}(77 \%)$, presented $\mathrm{CD}_{4}$ counts above 200 cells $/ \mathrm{mm}^{3}$ (75\%), had been receiving 
antiretroviral treatment for at least 18 months (52\%) and had never changed their therapeutic regimen $(56 \%)$. All patients received regimens containing Nucleoside Analogue Reverse Transcriptase Inhibitors (NRTI), $42 \%$ received Protease Inhibitors (PI) in association, $45 \%$ were treated with Non Nucleoside Reverse Transcriptase Inhibitors (NNRTI) and one patient received a regimen with all three types of drugs. One fifth of the patients had mean adherence below $60 \%$ whereas $71 \%$ showed adherence of $80 \%$ or greater.

The prevalence of undetectable final viral load increased with the level of mean adherence to antiretroviral treatment and the age of the patient; and it was lower with increasing viral load prior to adherence measurement and for patients receiving treatment with only NRTI. Female patients, duration of treatment less than 6 months and $\mathrm{CD}_{4}$ cell counts of 200 cells $/ \mathrm{mm}^{3}$ or higher gave a higher prevalence of undetectable final viral load; clinical stage B gave a lower prevalence, however statistical associations were weak for all these variables $(p=0.085-0.240)$. There was no evidence of association between undetectable final viral load and change of antiretroviral regimen $(\mathrm{p}=0.746)$ (Table 1).

The regression model showed that the odds of undetectable final viral load decreased as viral load increased prior to the adherence measurement was higher. The odds of undetectable viral load was $81 \%$ lower for patients whose viral load prior to the adherence measurement was $5.1 \log _{10}$ or greater, compared to those who had viral loads prior to the adherence measurement lower than $3.0 \log _{10}$, adjusted for sex, age, clinical stage, current immune status, duration of treatment, group of drugs, mean adherence and interval between the two measurements of viral load (Table1).

The crude odds ratio of undetectable final viral load was positively associated with the level of adherence to antiretroviral treatment. After adjustments for sex, age, viral load prior to adherence measurement, clinical stage, current immune status, duration of treatment, group of drugs and interval between the two measurements of viral load, the odds of undetectable final viral load was 3.6 times higher in patients taking
$60 \%$ to $79 \%$ of the medication prescribed and more than 4 times higher for patients taking $80 \%$ or more of the medication prescribed, when compared to the odds of those whose adherence was less than $60 \%$. However, wide confidence intervals indicate the imprecision of this measurement (Table 1).

The odds of undetectable final viral load was more than 3 times higher for patients treated for less than six months than for those treated for 18 months or more, after adjustment for sex, age, viral load previous to the adherence measurements, clinical stage, current immune status, group of drugs used, mean adherence and interval between two measurements of viral loads (Table 1).

Patients receiving regimens including only NRTI had crude odds of undetectable final viral load $70 \%$ lower than those whose regimens also included NNRTI, but the odds ratio decreased to $55 \%$ when the confidence interval included the unit after adjustments for sex, age, viral load prior to adherence measurement, clinical stage, current immune status, duration of treatment, mean adherence and interval between two measurements of viral load (Table 1). The analysis of the number of drugs per regimen revealed that $26 \%$ of the patients who received a double regimen had an undetectable final viral load; this percentage was $50 \%$ for patients treated with triple and quadruple regimens $\left(X^{2} 2 \mathrm{df}=6.397 ; \mathrm{p}=0.041\right)$. In the crude model, patients treated with the double regimen had odds of reaching an undetectable final viral load $67 \%$ lower than those receiving a triple regimen $(\mathrm{OR}=0.33$; $\mathrm{CI} 95 \% 0.13$ $0.82 ; \mathrm{p}=0.041$ ), but this result lost statistical significance after adjustments for sex, age, viral load prior to adherence measurement, clinical stage, current immune status, duration of treatment, mean adherence and interval between the two measurements of viral load $(\mathrm{OR}=0.48$; CI 95\% 0.16-1.40; $\mathrm{p}=0.376)$. It was not possible to assess the effect of the number of drugs independent from the effect of the pharmaceutical group of drugs because double regimens contained NRTI only.

Patients between 16 and 24 years of age had odds of undetectable final viral loads $63 \%$ lower than those of age 45 or higher, but the statistical evidence was 
Table 1. Number of patients, percentage of undetectable viral load and odds ratios of undetectable viral load for the variables studied

\begin{tabular}{|c|c|c|c|c|}
\hline & \multirow{2}{*}{$\begin{array}{c}\text { Subjects } \\
\text { N }\end{array}$} & \multirow{2}{*}{$\begin{array}{c}\text { Viral Load }<80 \\
\%\end{array}$} & \multicolumn{2}{|c|}{ Odds Ratio (CI 95\%) } \\
\hline & & & Crude & Adjusted $^{1}$ \\
\hline \multicolumn{5}{|l|}{$\overline{\operatorname{Sex}}$} \\
\hline Masculine & 158 & 44.3 & 1 & 1 \\
\hline \multirow[t]{2}{*}{ Feminine } & 86 & 55.8 & $1.59(0.94-2.69)$ & $1.50(0.81-2.76)$ \\
\hline & & $X^{2} 1 \mathrm{df}=2.96, \mathrm{p}=0.085$ & $\mathrm{p}=0.085$ & $\mathrm{p}=0.196$ \\
\hline \multicolumn{5}{|l|}{ Age (years) } \\
\hline $16-24$ & 29 & 34.5 & $0.37(0.14-0.9994)$ & $0.36(0.12-1.09)$ \\
\hline $25-34$ & 87 & 46 & $0.60(0.28-1.28)$ & $0.53(0.23-1.22)$ \\
\hline $35-44$ & 87 & 50.6 & $0.72(0.34-1.53)$ & $0.61(0.26-1.41)$ \\
\hline \multirow[t]{2}{*}{${ }^{3} 45$} & 41 & 58.5 & 1 & 1 \\
\hline & & $X^{2} 1 \mathrm{df}=4.08, \mathrm{p}=0.043$ & $\mathrm{p}=0.226$ & $\mathrm{p}=0.283$ \\
\hline \multicolumn{5}{|c|}{ Viral load prior to adherence measurement $\left(\log _{10}\right)$} \\
\hline$<3.0$ & 67 & 61.2 & 1 & 1 \\
\hline $3.0-3.6$ & 43 & 53.5 & $0.73(0.34-1.58)$ & $0.74(0.31-1.74)$ \\
\hline $3.7-4.3$ & 50 & 40 & $0.42(0.20-0.89)$ & $0.49(0.22-1.12)$ \\
\hline $4.4-5.1$ & 54 & 46.3 & $0.55(0.26-1.13)$ & $0.68(0.30-1.57)$ \\
\hline \multirow[t]{2}{*}{${ }^{3} 5.2$} & 30 & 30 & $0.27(0.11-0.68)$ & $0.19(0.06-0.58)$ \\
\hline & & $X^{2} 1 \mathrm{df}=8.46, \mathrm{p}=0.004$ & $\mathrm{p}=0.032$ & $\mathrm{p}=0.035$ \\
\hline \multicolumn{5}{|l|}{ Clinical Stage } \\
\hline A & 34 & 47.1 & $0.87(0.42-1.81)$ & $0.73(0.30-1.77)$ \\
\hline B & 22 & 31.8 & $0.46(0.18-1.17)$ & $0.54(0.18-1.60)$ \\
\hline \multirow[t]{2}{*}{$\mathrm{C}$} & 188 & 50.5 & 1 & 1 \\
\hline & & $X^{2} 2 \mathrm{df}=2.85, \mathrm{p}=0.240$ & $\mathrm{p}=0.240$ & $\mathrm{p}=0.472$ \\
\hline \multicolumn{5}{|c|}{ Current Immune Status } \\
\hline $\mathrm{CD} 4<200 \mathrm{cell} / \mathrm{mm}_{3}^{3}$ & 61 & 41 & $0.67(0.37-1.21)$ & $0.65(0.32-1.32)$ \\
\hline \multirow[t]{2}{*}{$\mathrm{CD}^{3} 200 \mathrm{cell} / \mathrm{mm}^{3}$} & 183 & 50.8 & 1 & 1 \\
\hline & & $X^{2} 1 \mathrm{df}=1.78, \mathrm{p}=0.182$ & $\mathrm{p}=0.182$ & $\mathrm{p}=0.230$ \\
\hline \multicolumn{5}{|c|}{ Duration of Treatment (months) } \\
\hline$\leq 6$ & 23 & 56.5 & $1.71(0.69-4.21)$ & $3.37(1.09-10.46)$ \\
\hline $7-17$ & 103 & 52.4 & $1.45(0.85-2.46)$ & $1.64(0.89-3.03)$ \\
\hline \multirow[t]{2}{*}{${ }^{3} 18$} & 118 & 43.2 & 1 & 1 \\
\hline & & $X^{2} 1 \mathrm{df}=2.42, \mathrm{p}=0.120$ & $\mathrm{p}=0.280$ & $\mathrm{p}=0.063$ \\
\hline \multicolumn{5}{|l|}{ Group of Drugs* } \\
\hline NRTI & 30 & 26.7 & $0.30(0.12-0.74)$ & $0.45(0.16-1.32)$ \\
\hline NRTI+PI & 103 & 47.6 & $0.76(0.44-1.30)$ & $0.77(0.41-1.47)$ \\
\hline \multirow{2}{*}{ NRTI+NNRTI } & 110 & 54.5 & 1 & 1 \\
\hline & & $X^{2} 2 \mathrm{df}=7.61, \mathrm{p}=0.022$ & $\mathrm{p}=0.022$ & $\mathrm{p}=0.312$ \\
\hline \multicolumn{5}{|l|}{ Changes of Regimen } \\
\hline No & 137 & 47.4 & 1 & \\
\hline \multirow[t]{2}{*}{ Yes } & 107 & 49.5 & $1.09(0.66-1.80)$ & \\
\hline & & $X^{2} 1 \mathrm{df}=0.105, \mathrm{p}=0.746$ & $\mathrm{p}=0.746$ & \\
\hline \multicolumn{5}{|l|}{ Mean Adherence } \\
\hline$<60 \%$ & 52 & 19.2 & 1 & 1 \\
\hline $60-79 \%$ & 18 & 50 & $4.20(1.33-13.30)$ & $3.63(1.02-12.98)$ \\
\hline $80-94 \%$ & 42 & 57.1 & $5.60(2.23-14.07)$ & $4.88(1.80-13.28)$ \\
\hline \multirow{2}{*}{${ }^{3} 95 \%$} & 132 & 56.8 & $5.53(2.56-11.95)$ & $4.07(1.73-9.53)$ \\
\hline & & $X^{2} 1 \mathrm{df}=18.9, \mathrm{p}<0.001$ & $\mathrm{p}<0.001$ & $\mathrm{p}=0.003$ \\
\hline Total Sample & 244 & 48.4 & & \\
\hline
\end{tabular}

1. adjusted for the interval between the two measurements of viral load and other variables in the Table, except for changes of regimen. $*$ A patient who received NRTI + NNRTI+ PI was excluded. 
weak after adjustment for sex, viral load prior to adherence measurement, clinical stage, current immune status, duration of treatment, group of drugs, adherence and interval between two measurements of viral loads $(\mathrm{OR}=0.36$; CI 95\% 0.12-1.09) (Table 1).

There was no evidence of a difference in odds ratio of undetectable final viral loads for sex, clinical stage, current immune status and change of therapeutic regimens.

\section{Discussion}

The purpose of this study was to investigate the risk factors for undetectable final viral load in non-pregnant adults who were receiving antiretroviral treatment. Blood samples from all patients were drawn at a phase of clinical stability, at least 4 weeks after immunizations, or intercurrent infections, and were analyzed by the same laboratory. Viral load was measured by the NASBA method (Nuclisens, Organon Teknika), whose limit of detection is $80 \mathrm{copies} / \mathrm{ml}$. This threshold of detection has been considered clinically acceptable because it is associated with immune system improvement, better quality of life and greater survival rates [1-5], and because the levels of viral load associated with high risk for viral resistance are unknown due to difficulties in identifying genotypes and phenotypes of HIV for viral loads lower than 1,000 copies/ml [6].

It is difficult to compare the results of different studies because of the differences in study design and techniques used for measuring viral loads (NASBA, PCR, bDNA) whose threshold of detection are only reasonably comparable $[6,10,26$ 27]. Similar to other studies $[11,18,28]$, the prevalence of undetectable viral load was low $(48.4 \%)$. It is possible that this prevalence has been overestimated because the patients who were dead and those who refused to participate in the study, were not found or did not have their viral loads measured $(n=78,24 \%)$ would have shown a lower prevalence of undetectable final viral load than the patients included in the study.
According to other studies [5.15-17], showing that the prevalence of undetectable viral load increases with the level of adherence to the treatment, in the present study patients with adherence between $80 \%$ and $94 \%$ and those with $95 \%$ or more had the odds of undetectable final viral load four times higher than that shown by patients with adherence of less than $60 \%$, although the large confidence intervals indicate imprecision in this measurement. These results are also in accordance with studies which observed that the viral load decreases as the adherence level increases $[13,14]$.

Time in treatment was another predictor of undetectable viral load. Patients being treated for less than six months had higher odds of undetectable viral load than patients with a minimum of 18 months; however, there was a wide confidence interval, probably because the number of patients treated for less than 6 months was small. It is possible that this result is due to a rapid decrease in viremia that occurs in the first 4 to 6 weeks of treatment when a reduction of at least 1.0 $\log _{10}$ or $90 \%$ of the initial viremia is expected [6]. This is likely because the viral load prior to the adherence measurement of patients in treatment for less than 6 months corresponded to the viral load at the beginning of the treatment; furthermore, cohort studies suggest that reductions in viral loads are greater in the first months of treatment $[11,12]$. Another possibility is that after 18 months there is a higher probability of viral rebound due to resistance, problems of drug absorption and periods of low adherence. Longitudinal studies measuring viral loads at small intervals are still needed to assess this hypothesis.

Viral load at the beginning of treatment had been associated with undetectable viral load $[5,18,20,21]$, but we did not investigate the effects of this variable. The study used measurements of viral load routinely collected by the service and by the end of 1999 this exam was still not available in the service. The alternative was the use of viral load measured prior to the adherence measurement. As expected, the odds of undetectable final viral load were negatively associated with the viral load prior to adherence measurement. Another limitation of using routine measurements of viral loads was that the interval between the two 
measurements of viral load was not equal for all patients, but this interval was taken into account in the multivariate model.

Another important variable was the group of drugs used. Regimens that included only NRTI showed odds of undetectable final viral load $70 \%$ lower than those regimens containing NRTI and NNRTI, although the effect was not statistically significant in the multivariate model, probably due to the low power for detecting effects of this magnitude. Similarly, the odds of undetectable final viral load was higher for triple than for double regimens, which in fact are regimens containing only NRTI. In other countries, double regimens are being gradually substituted by regimens including three or more drugs-HAART, Highly Active Antiretroviral Therapy. Some studies suggest that regimens including two drugs have lower odds of undetectable viral load than regimens with three or more drugs [22,23]. Studies with greater sample size are needed to examine the effects of group of drugs and number of drugs on the viral load.

Similarly to other studies $[18,19]$, the prevalence of undetectable viral load increased with age. Patients under 25 years of age showed lower odds of undetectable viral load than patients over 45 years old; however, the statistical evidence was weak, probably due to the low power of this study. Studies with larger sample sizes are needed to assess the effect of age on the viral load.

In our study, the prevalence of undetectable viral load was low (48\%). The most important predictor of undetectable viral load was the level of treatment adherence. The prevalence of undetectable viral load was $19 \%$ for patients with less than $60 \%$ adherence, which was three times less than the prevalence observed in patients with treatment adherence of $80 \%$ or greater. Therefore, interventions to improve treatment adherence are needed. Some studies suggest that pharmaceutical assistance (including explanation to the patient regarding the correct use of the medication [29]) as well as other motivational interventions aimed at increasing patient's self-efficacy for taking the medication in difficult situations would help [16,30-33].

\section{Acknowledgments}

This article originated from the masters dissertation of Marysabel Pinto Telis Silveira; the authors are thankful to the Catholic University of Pelotas, which granted the Masters Scholarship to Marysabel Pinto Telis Silveira and a Scientific Initiation Scholarship for the project; to "Fundação de Amparo à Pesquisa" (Foundation for Research Development) from Rio Grande do Sul State (FAPERGS- Process Number 990161.2) for the grant provided to José Carlos de Carvalho Leite, responsible for the research project 'Motivation for the treatment as a predictor of adherence to antiretrovirals in southern Brazil', which gave origin to the present study.

\section{References}

1. Palella F.J., Delaney K.M., Moorman A.C., et al. Declining morbidity and mortality among patients with advanced human immunodeficiency virus infection. N Engl J Med 1998;338:853-60.

2. Center for Disease Control and Prevention. Revised classification system for HIV infection and expanded surveillance case definition for AIDS among adolescent and adults. MMWR 1993;41:1-19.

3. Mocroft A., Vella S., Benfield T.L., et al. Changing patterns of mortality across Europe in patients infected with HIV1. Lancet 1998;352:1725-30.

4. Hogg R.S., Heath K.V., Yip B., et al. Improved survival among HIV-infected individuals following initiation of antiretroviral therapy. JAMA 1998;279:450-4.

5. Paterson D.L., Swindells S., Mohr J.,et al. Adherence to protease inhibitor therapy and outcomes in patients with HIV infection. Ann Intern Med 2000;133:21-30.

6. Rashid M., Schechter M. Manual de HIV/AIDS. Rio de Janeiro, Br: Revinter, 2001.

7. Skidmore S.J., Zuckerman M., Parry J.V. Accuracy of plasma HIV RNA quantification: a multicentre study of variability. J Med Virol 2000;61:417-22.

8. Hubert J.B., Burgard M., Dussaix E., et al. Natural history of serum HIV-1 RNA levels in 330 patients with a know date of infection. AIDS 2000; 14:123-31.

9. Eron J.J., Yetzer E.S., Ruane P.J., et al. Efficacy, safety, and adherence with a twice-daily combination lamivudine/ zidovudine tablet formulation, plus a protease inhibitor, in HIV infection. AIDS 2000; 14:671-81. 
10. BartlettJ.G., GallantJ.E. Medical management ofHIV infection. Baltimore, MA: Johns Hopkins University Press, 2001.

11. Roca B., Gómez C.J., Arnedo A. Adherence, side effects and efficacy of stavudine plus lamivudine in treatmentexperienced HIV-infected patients. J Infect 2000;41:50-4.

12. Yerly S., Kaiser L., Perneger T.V., et al. Time of initiation of antiretroviral therapy: impact on HIV-1 viraemia. AIDS 2000; 14:243-9.

13. Gifford A.L., Bormann J.E., Shively M.J., et al. Predictors of self-reported adherence and plasma HIV concentrations in patients on multidrug antiretroviral regimens. JAIDS 2000;23:286-95.

14. Haubrich R.H., Little S.J., Currier J.S., et al. The value of patient-reported adherence to antiretroviral therapy in predicting virologic and immunologic response. AIDS 1999; 13:1099-1107.

15. Bansberg D.R., Hecht F.M., Charlebois E.D., et al. Adherence to protease inhibitors, HIV-1 viral load, and development of drug resistance in an indigent population. AIDS 2000; 14:357-66.

16. Tuldrá A., Fumaz C.R., Ferrer M.J., et al. Prospective randomized two-arm controlled study to determine the efficacy of a specific intervention to improve long-term adherence to highly active antiretroviral therapy. JAIDS 2000;25:221-8.

17. Kleeberger C.A., Phair J.P., Strathdee A.S, et al. Determinants of heterogeneous adherence to HIVantiretroviral therapies in the multicenter AIDS cohort study. JAIDS 2001;26:82-92.

18. Valdez H., Lederman M.M., Wolley I., et al. Human immunodeficiency virus 1 protease inhibitors in clinical practice. Arch Intern Med 1999; 159:1771-6.

19. Grabar S., Pradier C., Corfec E.L., et al. Factors associated with clinical and virological failure in patients receiving a triple therapy including a protease inhibitor. AIDS 2000; 14 :141-9.

20. Paris D., Ledergerber B., Weber R., et al. Incidence and predictors of virologic failure of antiretroviral triple-drug therapy in a community-based cohort. Aids Research and Human Retroviruses 1999;15:1631-8.

21. Paredes R., Puig T., Arnó A., et al. High-dose saquinavir plus ritonavir: long-term efficacy in HIV-positive protease inhibitor-experienced patients and predictors of virologic response. JAIDS 1999;22:132-8.

22. Muir D., White D., King J., et al. Predictive value of the ultrasensitive HIV viral load assay in clinical practice. J Med Virol 2000;61:411-6.

23. García F., Alonso M.M., Romeu J., et al. Comparison of immunologic restoration and virologic response in plasma, tonsillar tissue, and cerebrospinal fluid in HIV-1 infected patients treated with double versus triple antiretroviral therapy in very early stages: The Spanish EARTH-2 Study. J Acquir Immune Defic Syndr 2000;25(1):26-35.
24. Ministério da Saúde do Brasil. Recomendações para terapia antiretroviral em adultos e adolescentes infectados pelo HIV-2000. http:/www.aids.gov.br/ assistencia/concenso_brasileiro2000.doc; acessada em 09/07/2001 e 22/01/2001.

25. Centers for Disease Control and Prevention Report of the NIH panel to define principles of therapy of HIV infection and guidelines for the use of antiretroviral agents in HIV-infected adults and adolescents TM. US. Department of Health and Human Services. Atlanta, 2000.

26. Berndt C., Müller U., Bergmann F., et al. Comparison between a nucleic acid sequence-based amplification and branched DNA test for quantifying HIV RNA load in blood plasma. J Virol Methods 2000;89:177-81.

27. Schuurman R., Descamps D., Weverling G.J., et al. Multicenter comparison of three commercial methods for quantification of human immunodeficiency virus type 1 RNA in plasma. J Clin Microbiol 1996; Dec:3016-22.

28. Clough L.A., DÁgata E., Raffanti S., Haas D.W. Factors that predict incomplete virological response to protease inhibitor-based antiretroviral therapy. Clin Infect Dis 1999;29:75-84.

29. Nichols-English G., Poirier S. Optimizing adherence to pharmaceutical care plans. J Am Pharm Assoc 2000;40:475-85.

30. Mostashari F., Riley E., Selwyn P.A., Altice F.L. Acceptance and adherence with antiretroviral therapy among HIVinfected women in correctional facility. J Acquir Immune Defic Syndr 1998; 18:341-8.

31. Gordillo V. Del Amo J., Soriano V., Gonzalez-Lahoz J. Sociodemographic and psychological variables influencing adherence to antiretroviral therapy. AIDS 1999; 13:1763-9.

32. Catz S.L., Kelly J.A., Bogart L.M., Benotsch E.G., McAuliffe T.L. Patterns, correlates, and barriers to medication adherence among persons prescibed new treatment for HIV disease. Health Psychology 2000;19(2):124-133.

33. Singh N., Berman S.M., Swindells S., et al. Adherence of human immunoderficiency virus-infected patients to antiretroviral therapy. Clin Infec Dis 1999;29:824-830. 